\title{
Women experienced chronic fatigue syndrome and fibromyalgia as stigmatising
}

\author{
Asbring P, Närvänen AL. Women's experiences of stigma in relation to chronic fatigue syndrome and fibromyalgia. Qual \\ Health Res $2002 \mathrm{Feb} ; 12: 148-60$. \\ QUESTIONS: Do women with chronic fatigue syndrome (CFS) or fibromyalgia \\ experience stigmatisation? What strategies do they use to avoid stigma?
}

\section{Design \\ Grounded theory, based on symbolic interactionism.}

\section{Setting}

2 hospitals in Sweden.

\section{Patients}

25 women (age range 32-65 y) who were diagnosed with CFS $(n=12)$ or fibromyalgia $(n=13)$. Mean duration of illness before diagnosis was 9 years and after diagnosis was 2 years.

\section{Methods}

Each patient participated in 1 semistructured interview of 60-150 minutes. Questions focused on the women's and other people's views of the illness and strategies for dealing with the illness. Interviews were transcribed verbatim and analysed using the constant comparison method.

\section{Main findings}

Women reported 3 aspects of their illness that were stigmatising. (1) Questioning of their morality related to women's feelings that their moral character was called into question by others challenging the veracity of their illness experience. They attributed this questioning to the lack of visible external signs of illness. Questioning occurred, for example, at work, where they felt accused of being "work shy". Most women also felt that providers questioned their credibility after tests revealed no pathological problems. They felt that providers regarded them as malingerers, with concocted non-existent or exaggerated problems. (2) Women experienced stigma in relation to the psychologising of symptoms. Some felt that physicians categorised problems as fictitious or related to psychological reasons before doing a proper examination. Others described dualistic thinking, where in the absence of objective findings to verify physical illness, physicians postulated a psychological cause and sometimes referred women to psychiatric or psychological treatments. (3) Although formal diagnosis legitimised women's problems, it also had implications for stigmatisation. Women felt the term CFS lacked legitimacy among providers and was easily belittled by others because of the general nature of fatigue. Fibromyalgia was thought to be depreciated as a "women's" condition.

Women developed contextual strategies to avoid stigma. Keeping a distance from others: women withdrew from some areas of social life. They withdrew from care providers, delaying seeking care or turning to alternative medicine. Some constantly saw different physicians to avoid being seen as demanding. Concealing: some women tried to maintain a façade of a happy healthy person, only to collapse later when they returned home. Retaining certain aspects of social life such as work was also seen as a way of living normally. Spreading or withholding information: women controlled information and "played up different identities for different publics". Some women distributed written information about the disease to family, friends, and providers, and encouraged them to participate in information sessions. Withdrawing from or approaching other patients: women experienced contradictory feelings about fellow patients. They often had negative feelings about fellow patients, whom they felt were too focused on their illness. Other women described feelings of acceptance and solidarity with fellow patients.

\section{Conclusions}

Women experienced chronic fatigue syndrome and fibromyalgia as stigmatising in relation to others questioning their morality, the psychologising of their symptoms, and the diagnosis itself. They used several strategies to minimise the experience of stigma.

Sources of funding: Swedish Foundation for Health Care Sciences and Allergy Research and the Swedish

Rheumatism

Association.

For correspondence: $P$ Åsbring, Centre for Development of Health Services, Department of Public Health Sciences at Karolinska Institutet, Stockholm, Sweden.

pia.asbring@smd.sll.se

\section{COMMENTARY}

Any clinician who has taken the trouble to get to know a patient with fibromyalgia or CFS will recognise the basic finding of the study by Åsbring and Närvänen - patients attending specialist clinics with either condition (the similarities between the 2 outweigh the differences) feel acutely a sense of discrimination and stigmatisation. Many describe negative interactions with the medical profession. ${ }^{1}$ This is most acute when doctors are perceived to be "psychologising" the condition. Indeed, patients in this study found the act of prescribing antidepressants to be "violating". This is regrettable because evidence exists that antidepressants can reduce pain, fatigue, and sleep disturbances in patients with fibromyalgia, ${ }^{2}$ although similar evidence does not exist for patients with CFS.

These findings have important clinical implications. Clinicians need to accept the reality of suffering and the legitimacy of the diagnosis and to work together with patients in a supportive relationship. The battle of diagnosis is one from which no one emerges a winner - "if you have to prove you are ill, you can't get better".

The study by Åsbring and Närvänen was done in a specialist care setting. Patients in specialist clinics are not representative of the wider patient population. In particular, many patients seen in primary care settings perceive their symptoms differently and have a broader view of their illness, which incorporates elements of physical, social, and psychological causation. ${ }^{4}$ It would be an error to extrapolate the findings for this selected population to the wider population of patients.

Simon Wessely, MD, MRCP, MRCPsych, MA, MSc Guy's, King's and St Thomas's School of Medicine and Institute of Psychiatry London, UK

Deale A, Wessely S. Patients' perceptions of medical care in chronic fatigue syndrome. Soc Sci Med 2001:52:1859-64.

Arnold LM, Keck PE Jr, Welge JA. Antidepressant treatment of fibromyalgia. A meta-analysis and review. Psychosomatics 2000;41:104-13.

Hadler NM. If you have to prove you are ill, you can't get well. The object lesson of fibromyalgia. Spine 1996:21:2397-400.

Euba R, Chalder T, Deale A et al. A comparison of the characteristics of chronic fatigue syndrome in primary and tertiary care. Br J Psychiatry 1996;168:121-6. 